\title{
Laboratory Study on Submarine Debris Flow
}

Mei Yin ${ }^{1}$, Yi Rui $^{2 \downarrow}$

${ }^{1}$ Dr. Mei Yin

Schofield Centre, Department of Engineering

University of Cambridge, UK.

myin0915@gmail.com

${ }^{2}$ Dr Yi Rui

Centre for Smart Infrastructure \& Construction, Department of Engineering,

University of Cambridge, UK.

yr228@cam.ac.uk

${ }^{\vee}$ Corresponding Author: Department of Engineering, Trumpington Street, Cambridge, CB2 1PZ, UK.yr228@cam.ac.uk 


\begin{abstract}
Submarine debris flows were studied through a set of laboratory tests to investigate the flow characteristics and the effects of varying the water content. These tests used the Kaolin clay with water content from $125 \%$ to $185 \%$ as an artificial marine clay. The observed flow behaviour confirmed that submarine debris flows can be divided into strongly coherent flows and weakly coherent flows dependent on the shear strength of sliding material. A deeper understanding of the flow behaviour of submarine debris flows has been established through the particle image velocimetry (PIV) technique. The direction of a strongly coherent flow is parallel to the slope with steady flow velocity. In contrast, the velocity distribution of a weakly coherent flow is in disorder, due to ambient water penetrating the flow head. In this study, a densimetric Froude number $\mathrm{Fr}_{\mathrm{d}}$ is presented as the indicator for the threshold of hydroplaning, which occurs if $\mathrm{Fr}_{\mathrm{d}}$ is greater than 0.3 . In addition, the dimensionless yield stress, $\widehat{\mathrm{s}_{\mathrm{u}}}$, is introduced to determine the onset of weakly coherent flow. The threshold value of $\widehat{\mathrm{s}_{\mathrm{u}}}$ between strongly and weakly coherent flows is around 0.25.
\end{abstract}

\title{
Keywords
}

Submarine debris flows, hydroplaning, debris flow, turbidity current 


\section{Background}

Submarine debris flows are considered to be one of the most serious geohazards in offshore and coastal areas. Coastal infrastructure and offshore facilities such as pipelines, communication cables and oil platforms are at high risk from submarine debris flows. An example of submarine cable damage happened in the Grand Banks slide of 1929 where the debris flow and resulting turbidity current broke a series of submarine cables nearly $600 \mathrm{~km}$ away from the debris flow initial zone (Hampton et al., 1996; Masson et al., 2006). Another tremendous potential hazard associated with submarine debris flows is tsunamis. On July 17, 1998, the Papua New Guinean tsunami struck a $20 \mathrm{~km}$ section of the coast with waves up to $15 \mathrm{~m}$ high, killing 2,200 people (Masson et al., 2006). Although the impact of submarine debris flows is limited to coastal areas, their destructive power can be enormous. For this reason, in recent years submarine debris flows have been one of the central scientific topics in offshore engineering. Hampton (1972) described submarine landslides as having three stages: landsliding, debris flow and turbidity-current flow. This can also be identified by the volume fraction of the solid in the moving mass (Pudasaini 2014; Kafle et al. 2016). Boukpeti et al. (2012) described the entire process of submarine landslides, including slide failure, run-out and fluidisation, which are accompanied by a change in strength of more than three orders of magnitude, as shown in Figure 1. The similar conclusions have been published by many other researchers (Schwab et al., 1996; Locat \& Lee, 2000; Marr et al., 2002; Masson et al., 2006). Submarine debris flow can be triggered by many causes, like rapid deposition, hurricanes, volcanic activity earthquakes or climate change. But the the initiation of debris flow is not within the discussion of this paper. The focus of this paper is to discuss the flow characteristics of a submarine debris flow, by assuming it is already triggered.

Figure 1. Schematic diagram of key submarine slide characteristics (after Boukpeti et al. 2012) 
Submarine debris flows are difficult to observe directly, and so it is helpful to use physical subaqueous modelling tests to observe their behaviour to obtain an insight into submarine debris flows. Mohrig et al. (1998) carried out a series of experiments of muddy subaqueous and subaerial debris flows to demonstrate hydroplaning, showing that a thin layer of water intrudes into the front underneath of subaqueous debris flows. Marr et al. (2001) investigated the role of clay and water content in flow dynamics and depositional structures. Their main finding was that the observed flow mechanics and resulting depositional features are strongly tied to the coherence of the debris flow. Ilstad et al. (2004a, 2004b) performed a series of experiments using debris flows with varying clay/sand ratios to investigate the pressure distribution during the flow and depositional processes. One of their key findings was that the process of hydroplaning formation at the nose is more obvious in clay-rich flows. The work of Breien et al. (2007) involved a comparative study on subaqueous and subaerial debris flows. The results showed the ambient and interstitial fluid has a large effects on the behaviour of subaqueous debris flows. These tests, discussed above, investigated different stages of submarine debris flow, including intact debris flow, the occurrence of hydroplaning and turbidity currents, in terms of flow characteristics and behaviour, velocity profile, change in pore pressure and effective stress. However, few refer to the quantitative thresholds of hydroplaning and turbulent currents.

This paper describes a series of physical tests of subaqueous debris flows to observe flow behaviour with changing water content and slide slope. The model slope was fitted with miniature sensors to measure the pore pressure at two different locations beneath the debris flow, and three digital cameras were used to capture the debris motion. Erosion, entrainment and deposition are important phenomena in mass flows as these processes can tremendously change the flow characteristics and flow mobility in terms of enhanced travel distance and flow velocity (Dan et al. 2007). So entrainment of water from beneath the slide into the flow was investigated and the threshold of turbulent flow was analysed based on the relationship between stagnation pressure and shear strength. 


\section{Experiment details and procedures}

\subsection{Experimental setup}

The submarine debris flow experiments were performed on a slope inserted inside a glass-walled tank (Figure 2). The water tank selected for this category was a steel box with a perspex wall, $41.5 \mathrm{~cm}$ long, $50 \mathrm{~cm}$ high and $10.5 \mathrm{~cm}$ wide. A $70 \mathrm{~cm}$ long, 10.5 $\mathrm{cm}$ wide slope was suspended within the tank to simulate the sea bed that the slide flows down. A funnel was used to trigger the debris flow. The diameter of funnel gate was $5 \mathrm{~cm}$. The slope was made of steel, and a foam layer was put on the steel surface, allowing pore pressure transducers (PPTs) to be embedded. Rubber seals were used on both sides of the slope in contact with the tank walls to provide stability and prevent scratches to the transparent window during testing. Different from real submarine debris flow, slippage between debris flow and slope bed is a very common phenomenon in this kind of experiments. Hence, the sandpaper was used to eliminate or reduce such phenomenon. Hence, a layer of sandpaper (P320) was attached to the slope surface. As the speed of submarine debris flows in the field can be very fast in the real situation, the channel was set at steep inclinations to achieve high velocities in a small model. Pore pressure pressures at the base of submarine debris flows has been of interest because they are crucial for the flow behaviour (Ilstad et al., 2004a). Three 1 Bar PPTs were embedded within grooves in the foam layer along the slope at $15 \mathrm{~cm}$ intervals to measure the pore pressure at the interface between the debris flow and slope bed. But considering the boundary effect, PPT3 was not activated.

\section{Figure 2 Illustration of the experiment.}

Because the slurry flow in the tests only lasted for a few seconds, high speed cameras were required to capture images. With the high speed of movement of the slurry flow 
down the slope within the water tank, a very short exposure time $(<100 \mathrm{~ms})$ was used to prevent blur in the images. Nevertheless, the short exposure time means that powerful lighting was required to ensure that enough light reached the camera sensor per exposure. In these tests, three high powered $(500 \mathrm{~W})$ flood lights were used.

\subsection{Choice of debris material for the experiments}

In this series of experiments, Kaolin clay was used as the debris flow material, because Kaolin represents a limiting case of charge activity among all clay minerals, being most inactive. (Marr et al., 2001; Ilstad et al., 2004a). On the other hand, one of the most important feature of marine clay near seabed is its extremely low shear strength, due to its high water content. Accordingly, the tests were carried out using Kaolin clay with a large variation in water content, from $125 \%$ to $185 \%$, corresponding to changes of flow behaviour from solid to more liquid. The clay slurries used in the experiments were characterized by the mass fractions of water and clay defined as the water content. The shear strength of the mixed clay slurries were calculated by the equation proposed by Locat \& Demers (1988):

$$
\mathrm{S}_{\mathrm{u}}=1.46(\mathrm{LI})^{-2.44} \quad 1.5 \leq \mathrm{LI} \leq 6
$$

The results are listed in Table 1.

\section{Table 1 Clay slurries used in the test}

\subsection{Experimental procedures}

The illustration of the experiment is shown in Figure 2. In general, the Kaolin clay slurry was mixed and poured into the funnel. When the slurry was full and reached the top of the funnel, the funnel gate was opened and the slurry flowed onto the slope within the water tank. In order to compare the effect of varying flow velocity, two slope angles were used in this test. The first series of tests was carried out on the slope with angle $68^{\circ}$, and the second series of tests used a slope angle of $57^{\circ}$. Particle 
image velocimetry (PIV) technique was used to track the soil during the model test. The detailed procedure for each test in this series is summarized as follows:

1. Tank was completely cleared and the Perspex window was cleaned and polished. Sandpaper (P320) was cut to the slope dimensions and to expose the PPTs.

2. The test tank was filled with tap water to the maximum level. Well-saturated PPTs were embedded in the slope suspended in the tank.

3. The soil sample was prepared by manually mixing Kaolin clay powder and fresh water to achieve the required water content. Ink was used to dye some of the clay slurry.

4. The slurry was poured into the funnel to a marked level. The volume of slurry was about 1.1 litres.

5. The funnel was put at the top of the tank above the slope. Then released the contents of the funnel under the water level.

6. Simultaneously, the data acquisition system was switched on and the MotionBLITZ EoSens high-speed camera started to record. The recording time was set up to record at a resolution of $1694 \times 1752$ pixels and $500 \mathrm{fps}$.

7. The elevation of the water surface during the sliding was measured by image analysis. This data was used to correct the PPT measurements later.

8. Measure the water content of slurries after each test.

\section{Results and Interpretation}

\subsection{Flow characteristics}

According to Marr et al. (2001) and Ilstad et al. (2004), submarine debris flows can be divided into strongly coherent flows, with absent front erosion and little effect on the front shape, and weakly coherent flows that experience dilated and turbulent suspension. On the other hand, if the flow speed is high enough, a layer of fluid intrudes under the front of a flow and therefore uplifts the flow head. The phenomena of an uplifted flow head is called 'hydroplaning' (Mohrig, et al., 1998). In the two 
series of experiments, the initial flow speed was different for different cases, due to the differing friction between the slurry and the funnel. Common to most but not all cases, the slurry with a high water content had a higher initial speed, which is also similar to the real situation. However, in some extreme cases, the large friction by the funnel may cause a breakage of the flow body. If it happens, the test needs to be redone.

Figure 3 shows three different types of submarine debris from the first series of tests (slope angle of $68^{\circ}$ ). For the purpose of additional flow visualization and image-based analysis, the Kaolin clay was coloured with blue dye. For an initial water content of $125 \%$, flows with a relatively low water content resulted in a substantially raised head, followed by a well-defined smooth boundary of flow body throughout the entire flow, without turbidity suspension (Figure 3 (125\%)). This kind of flow can be considered to be strongly coherent flows. In addition, the flow head lifts off the slope bed, and water intrudes further beneath the flow body when the flow speed increases, causing a water layer to exist between the flow body and the slope. So it can be called hydroplaning (Mohrig, et al., 1998). The other exclusive characteristic is that the flow head moves faster than other parts of the flow, and hence the thickness of the slurry body at the middle tends to become a little smaller. This phenomenon can be explained by the way that hydroplaning causes a basal lubricating water layer between the flow body and the slope, and therefore accelerates the speed of the front part, which detaches from the flow body, becaused reduced friction enhances the flow mobility. Between the mixtures with $142 \%$ and $146 \%$ water content, the flow head lifts up in the same way as a water content of $125 \%$, so hydroplaning again occurs. However it shows moderately dilated turbidity currents as it flows down the slope. Hence, the debris flow with a water content of $142 \%$ is at the transition between weakly and strongly coherent flows. Increasing the water content to $161 \%$ gives totally different submarine debris flow behaviour (weakly coherent flow). The turbidity current generated at the front can be found throughout the entire flow, along with a pronounced dilation of the flow body. However, there could be a dense flow 
layer along the slope beneath the turbidity current, as often observed in pyroclastic flows ( see, e.g., Pudasaini and Hutter, 2007). Water intrusion underneath the flow body is still observed. But the rigid debris flow body is no longer observed, compared to lower water content clay slurries. The flow transition from strongly to weakly coherent flows is due to the decrease of shear strength of the debris material. But this transition shows no abrupt changes.

Figure 3 First series of debris flows (slope angle of $68^{0}$ ) with different water content at (a) $15 \mathrm{~cm}$ and (b) $30 \mathrm{~cm}$ downslope from the funnel gate

In test series 2 the flow slurry at the low water content (from 125\% to 142\%) is characterized by a well-defined smooth boundary flow body throughout the entire flow similar to (Figure $3(125 \%)$ ). The difference is that turbidity currents is no longer visible for debris flow with water content of $142 \%$ compared to series 1 , due to the slower velocity caused by the smaller slope angle. By gradually increasing the water content to $146 \%$, the flow behaviour is similar to the debris flow (water content $142 \%$ ) in test series 1 . The head tends to lift up like a strongly coherent flow at the very beginning; however it shows a moderately dilated turbidity current as it flows down the slope due to the increased stagnation pressure caused by acceleration. A significant difference is seen when the water content increases to $161 \%$. The flow body is intensively fluidized with the entire head appearing to break up into a turbulent flow. Hence, it is difficult to distinguish the overlying turbidity current and main debris flow in the frontal zone.

Figure 4 First series of debris flows (slope angle of $57^{0}$ ) with different water content at (a) $15 \mathrm{~cm}$ and (b) $30 \mathrm{~cm}$ downslope from the funnel gate

\subsection{Analysis of velocity profiles}

The mechanism of submarine debris flows is quite complicated, and the flow behaviour is dominated by changes in water content and flow speed along as 
discussed above. Therefore particle image velocimetry (PIV) technique is introduced to carry out a quantitative analyse of the flow velocity. From the discussion mentioned in last section, it can be found that the behaviour of flow slurry can be considered as three types: strongly coherent flow, moderately coherent flow and weakly coherent flow. Figure 5 shows during the evolution of the displacement field over a 50 frames interval (0.1s).

Figure 5 PIV analysis of the behaviour of three different slurries with water content: (a) strongly coherent (125\%); (b) moderately coherent (146\%); (c) weakly coherent $(161 \%)$ from first series test (slope angle of $68^{0}$ ). Coordinate units are in $\mathbf{m m}$.

(1) Strongly coherent flows

In Figure 5 (a), the direction of flow is mostly parallel to the slope, and only a little difference in flow head is observed. This could be described by strongly coherent flows, a coherently deforming and sliding body with a uniform downward flow velocity about $0.6-0.8 \mathrm{~m} / \mathrm{s}$, which has a thickness about $40 \mathrm{~mm}$. The direction of velocity at the front of the flow deviates from the direction of the slope so that there is a water layer between the flow head and the slope surface. The extremely low flow velocity near the slope surface indicates the large friction between debris flow and slope bed. Hence, the use of sandpaper here was sufficient to avoid the slippage phenomenon for the debris flow material mixtures

(2) Moderately coherent flows

In contrast to strongly coherent flows, the velocity image in In Figure 5 (b) shows that the sliding process is not a unified motion, and instead the front gradually changes 
from a rigid head, as seen in the strongly coherent flow, to a fluidized front in weakly coherent flows. The velocities of the flow head increase to more than $1 \mathrm{~m} / \mathrm{s}$ as they progress down the slope, due to the lubricant fluid layer between the slurry and the slope. On the other hand, it shows a decreased thickness and velocity behind the front.

(3) Weakly coherent flows

In Figure 5 (c), as the water content increases, the debris flow completely transforms into a weakly coherent flow instead of a rigid flow, but yet not fully turbid, so that the flow with a turbulent head moves downslope along with a pronounced dilation of the flow body. The velocity distribution of the weakly coherent flow is in disorder, unlike the strongly coherent flow. This is because the water erodes the flow head, rendering it diffuse. It also shows a slight deposition during sliding process, a feature not seen in the strongly coherent flow.

\subsection{Change of water content}

The process of a submarine debris flow is accompanied by a change in water content, shear strength and flow behaviour, all of which are caused by water entrainment. Therefore it is necessary to measure the water content after each test as well as before. In this research, the initial water content of each sample was measured before the test. Once the test finished, the soil sample was taken out from the tank. The ambient water left on the surface was removed. And then the water content was measured based on the inner part of soil sample. The results are shown in Figure 6. Compared to the initial water content, the change after sliding process was very limited when the initial water content was below $142 \%$ in series 1 and $146 \%$ in series 2 , which agrees with the flow behaviour transition discussed above. For a strongly coherent flow the dynamic stress was sufficiently small compared to the permeability of the flow, which therefore precluded almost any ingestion of ambient water. As water content increased, the strength of the flow decreased. Ambient water mixed into the head of the flows as a 
consequence of the turbulence, which expanded the head and reduced their bulk density. Hence, the water content increased about $60 \%-80 \%$ for the weakly coherent flow with initial water contant large than $160 \%$. In addition, the change of water content in series 1 was larger than in series 2 , which indicated that higher flow velocity in series 1 leaded to a larger scale of water intrusion.

Figure 6. Water content of debris flow before and after test: (a) slope angle $\mathbf{6 8}^{\mathbf{0}}$; (b) slope angle $57^{0}$

\subsection{The threshold of hydroplaning}

As mentioned previously, hydroplaning of the subaqueous flow is caused by stagnation pressure which develops at the front of the slurry flow, great enough to modify the flow shape (De Blasio, et al., 2004; Ilstad, et al., 2004; Mohrig, et al. 1998). The stagnation pressure increases as the velocity accelerates, which deforms the head of the debris flow and enables a thin layer of water to penetrate into the interface between the bed and the debris. Once hydroplaning begins the flow head tends to be lifted by the ambient pressure underneath the flow head. The stagnation pressure can be estimated by (Mohrig, et al., 1998):

$$
P=0.5 \rho v^{2}
$$

where $\mathrm{P}$ is the stagnation pressure, $\rho$ is the density of the ambient water, and $\mathrm{v}$ is the velocity of the flow head.

Mohrig (1998) proposed that the occurrence of hydroplaning depends on whether the stagnation pressure $\mathrm{P}$ is able to support the average submerged debris-load, $\mathrm{P}_{\mathrm{d}}$ :

$$
P_{d}=\left(\rho_{b}-\rho\right) g h_{b} \cos \alpha
$$


where $\rho_{b}$ is the density of the slurry, $h_{b}$ is the average thickness of the slurry body, $\alpha$ is the slope angle, and $\mathrm{g}$ is the local gravity.

According to Mohrig (1998), the simple balance between $\mathrm{P}$ and $\mathrm{P}_{\mathrm{d}}$ can be used as an indicator of the onset of hydroplaning. Hence, Mohrig (1998) presented a densimetric Froude number, $\mathrm{Fr}_{\mathrm{d}}$, as the indicator:

$$
\mathrm{Fr}_{\mathrm{d}}=\frac{\mathrm{v}}{\sqrt{\left(\frac{\rho_{\mathrm{b}}}{\rho}-1\right) \mathrm{gh}_{\mathrm{b}} \cos \alpha}}
$$

Accordingly, by using Equation (4) $\mathrm{Fr}_{\mathrm{d}}$ for all cases can be calculated for different slurries against the travel distance, as shown in Figure 7. However, it is difficult to distinguish the overlying turbidity current and main debris flow for weakly coherent flow. In addition, depending the consistency of the sliding mud, the flow can be highly multiphasic and, therefore, the mud density may change drastically with time and velocity for weakly coherent flow. Hence, $\mathrm{Fr}_{\mathrm{d}}$ was only calculated for these strongly coherent flows. $\rho_{b}$ was assumed as a constant value, $h_{b}$ and $v$ used average values, which could be estimated by PIV analysis as discussed above.

Figure 7 Values of the densimetric Froude number $F r_{d}$ for (a) Test series 1; and (b) Test series 2.

According to the flow behaviour captured by the camera, hydroplaning happened from beginning to end for most cases. Only for slurry with a low water content (125\% in Figure 7(a); $125 \%$ and $130 \%$ in Figure 7(b)) was there no hydroplaning at the very beginning, but hydroplaning occurred afterwards as the slurry moves. This can be well explained by the $\mathrm{Fr}_{d}$ values plotted in Figure 7 (a \& b), in which the non-hydroplaning flow is highlighted by a dotted circle. For these cases, $\mathrm{F}_{\mathrm{rd}}$ is below 0.3 at the beginning, with $\mathrm{Fr}_{\mathrm{d}}$ exceeds 0.3 after a period of time. It also proves 
the hypothesis that hydroplaning will occur when the hydrodynamic pressure come close to balancing the average submerged debris-load. This threshold value of $\mathrm{Fr}_{\mathrm{d}}$ also agrees with the value proposed by Mohrig (1998), who presented a range of $\mathrm{Fr}_{\mathrm{d}}$ values of 0.3 to 0.4 for the onset of hydroplaning. The small difference may be due to the effects of water intrusion and deformation of flow body, which leads to an error in the calculation of average submerged debris-load. Hence, it can be concluded that the threshold value of $\mathrm{Fr}_{\mathrm{d}}$ was roughly 0.3 for both Test series 1 and Test series 2 .

\subsection{The threshold of turbulent flow}

As discussed above, the turbulent flow body appears with higher water content slurries, therefore it is assumed that the shear strength of the slurry can be considered to be a dominant factor. The turbulent flow body is caused by a low soil strength that is unable to resist the stagnation pressure around the debris flow head. Accordingly, such phenomena is considered as the amount of erosion from the debris flow front governed by the ratio of the flow shear strength, $s_{u}$, to the front velocity, $v$ (Hampton, 1972; Mohrig and Marr, 2003; Ilstad, et al., 2004). This relationship is expressed as the dimensionless, $\widehat{\mathrm{s}_{\mathrm{u}}}$ :

$$
\widehat{\mathrm{s}_{\mathrm{u}}}=\frac{\mathrm{s}_{\mathrm{u}}}{\mathrm{P}}
$$

where $\mathrm{P}$ is the stagnation pressure (as shown in Equation (2)). $\mathrm{s}_{\mathrm{u}}$ changes at every moment of the sliding, but it can be assessed by the change in water content, as shown in Figure 6. The water content at different travel distances can be calculated by linear interpolation between initial and final values. Based on Equation 1, 2 and 5, the $\widehat{\mathrm{s}_{\mathrm{u}}}$ can be calculated for each slurry at different distances by the given shear strength and varied stagnation pressure, as plotted in Figure 8.

According to the flow behaviour, shown in Figure 3 and Figure 4, the slurries with water content of $142 \%$ in series 1 and $146 \%$ in series 2 transforms from dense debris 
flows into dilated turbulent flows as the slurry flowed down the slope. This is due to the increase in stagnation pressure in the flow process. The debris flows with turbidity currents are highlighted by the dotted curve as shown in Figure 8. The threshold of turbulent flow can also be seen in the dimensionless shear strength, $\widehat{\mathrm{s}_{\mathrm{u}}}$. Debris flows with dilated turbulent current has $\widehat{\mathrm{s}_{\mathrm{u}}} \leq 0.25$. In series 1 the values of $\widehat{\mathrm{s}_{\mathrm{u}}}$ for the slurries with water content of $142 \%$ decreases from about 0.4 to 0.15 , and in series 2 , $\widehat{\mathrm{s}_{\mathrm{u}}}$ for the slurries with water content of $146 \%$ decreases from about 0.42 to 0.15 . This further confirms that $\widehat{\mathrm{s}_{\mathrm{u}}} \leq 0.25$ is the indicator for turbulent debris flow andthe transition from strongly coherent to moderately coherent flows happening over a relatively narrow range in value for the dimensionless, $\widehat{\mathrm{s}_{\mathrm{u}}}$. Hence, the flow transition from strongly to weakly coherent flow occurs at the ratio value $\widehat{\mathrm{s}_{\mathrm{u}}}$ of about 0.25 . This is close to the experiment results given by Mohrig and Marr (2003), in which the transition occurred at a $\widehat{\mathrm{s}_{\mathrm{u}}}$ value of about 0.2 . This difference is very small compared to the range of $\widehat{\mathrm{s}_{\mathrm{u}}}$ in the two series of test from 0.05 to 20 . Hence, it can be concluded that this threshold of turbulent flow, as a dimensionless value, is applicable to different cases, not affected by the difference of test geometry or flow material.

Figure 8 Values of the dimensionless shear strength, $\widehat{\mathrm{s}_{\mathbf{u}}}$ for (a) Test series 1; and (b) Test series 2.

Figure 9 illustrates the average values of the dimensionless shear strength for different water content. Compared to the slow and steady change of undrained shear strength, $\mathrm{s}_{\mathrm{u}}$, the dimensionless shear streng $\widehat{\mathbf{s}_{\mathbf{u}}}$ decreases sharply with the increase of water content in the range of strongly coherent flow. This is due to the quick increase in the flow speed and hence stagnation pressure when the water content increases. Two turning points are shown, $142 \%$ for test series 1 and $146 \%$ for test series 2, corresponding to the threshold of weakly coherent flow. In the range of coherently flow, $\widehat{\mathbf{s}_{\mathbf{u}}}$ showed noticeably slower change with the increase of water content, which indicated that the decrease of $\widehat{\mathbf{s}_{\mathbf{u}}}$ was more dependent on the decrease of undrained shear strength $s_{u}$, rather than the increase of stagnation pressure. This is because the 
debris body was broken into turbidity currents due to the large stagnation pressure from ambient water, which in turn reduces this stagnation pressure to a large extent.

Figure 9: Average values of the dimensionless shear strength, $\widehat{\mathbf{s}_{u}}$ for different water content

\subsection{Change of excess pore pressure}

The excess pore pressure under the sliding debris flows was recorded by two PPTs, and the water surface measured by image analysis to correct this data. The results are sown in Figure 10. Excess pore pressures from six flows are presented to show the dependence of pressure evolution on the slurry texture. Pressure readings were measured at the bed, and the pressure was recorded as the debris flow approached and ran over the transducer section. For each case, the peak point of PPT2 is about $0.3 \mathrm{~s}-0.5 \mathrm{~s}$ behind that of PPT1 due to the sliding flow reached these tow PPTs at different time. Three main pressure situations were found in the experiments. (A) Excess pore pressure with slight fluctuation (Figure 10 (a \& d)). In this situation, the soil has a relatively low water content (125\%), and the debris flow is strongly coherent. The soil is like a rigid block riding upon the bed as the debris flow moves, so only a little fluctuation is seen in this situation. The change in excess pore pressure is less than $0.06 \mathrm{kPa}$, much smaller than in the other cases. (B) Excess pore pressure with medium fluctuation (Figure $10(\mathrm{~b} \& \mathrm{e})$ ). Part of the soil grains are in close contact with the bed, and the other part are in suspension. Hence, a medium fluctuating pressure between $-0.03 \mathrm{kPa}$ and $0.14 \mathrm{kPa}$ is seen. (C) Excess pore pressure with rapid fluctuation (Figure 10 (c \& f)). The third situation represents a debris flow with high water content (185\%), and the flow becomes turbulent when it moves. All the soil grains may remain in suspension and collide occasionally with the bed. Hence, a large, rapidly fluctuating pressure is seen. Common to all, the excess pore pressure evolution profiles from first series test shows a larger fluctuation than from second series due to the difference in slope angle and flow velocity. Therefore, the shapes of excess pore pressure evolution profiles can thus be another indicator to distinguish between strongly and weakly coherent flows. On the other hand, the large fluctuation 
may cause some errors by PPTs, such as the negative excess pore pressure in Figure 10(b), due to the effects of moisture or electrical connections. But this only occurred at the end of test, hence the impact is limited.

\section{Figure 10 Excess pore pressure along the bed under the sliding debris.}

\section{Summary}

The submarine debris flows were modelled using two sets of laboratory tests. In these tests, the dynamics of subaqueous debris flows were investigated using a set of combined techniques, including high speed cameras to capture flow characteristics, the particle image velocimetry (PIV) technique to collect data on the velocity field inside the debris flow, and pore pressure transducers to measure changes in pore pressure.

Submarine debris flows can be divided to strongly coherent flows and weakly coherent flows according to the flow characteristics. In strongly coherent flows, the ambient water in front of the flow head provides stagnation pressure to the sliding flow head. Because of the high shear strength of clayey slurry, water intrudes into the space between the flow front head and the slope surface, rather than into the flow body. A higher water content slurry possesses a lower shear strength, and hence the debris flow becomes weakly coherent as the water content increases. For this type of debris flow, the flow head is broken due to water entry, resulting in the occurrence of turbidity current. The flow behaviour transforms from rigid debris flow to a turbulent flow at a water content of about $142 \%$ for test series 1 (slope angle $68^{\circ}$ ), and $146 \%$ for test series $2\left(\right.$ slope angle $\left.57^{\circ}\right)$.

The particle image velocimetry (PIV) technique provides a tool to collect and analyse data on the slurry velocity field for different positions and at different times inside the debris flow and the turbidity current. Within a strongly coherent flow the direction of flow is parallel to the slope, and the difference in flow velocity is very limited. In 
contrast, as the water content increases, the velocity distribution of a weakly coherent flow is in disorder, due to ambient water eroding the flow head.

It is common sense that hydroplaning occurs when the stagnation pressure is able to support the average submerged debris-load. In this study, a densimetric Froude number $\mathrm{Fr}_{\mathrm{d}}$ was used as the indicator for the threshold of hydroplaning, which occurs if the $\mathrm{Fr}_{\mathrm{d}}$ is greater than 0.3. This threshold value of $\mathrm{Fr}_{\mathrm{d}}$ also agrees with the conclusion proposed by Mohrig (1998). In addition, the dimensionless yield stress, $\widehat{\mathrm{s}_{\mathrm{u}}}$, was introduced in the research to determine the onset of weakly coherent flow. According to the test results, the flow behaviour transformation between strongly and weakly coherent flows happens when $\widehat{\mathrm{s}_{\mathrm{u}}}$ exceeds 0.25 .

Different types of submarine debris flow go with different types of pore pressure profiles. Strongly coherent slurry is in close contact with the bed and hence the pore pressure profile seems small and smooth. In weakly coherent slurry, the debris flow becomes dilated by turbidity currents due to the intrusion of water. The soil grains remain in suspension and occasionally collide with the bed, and are associated with a large and rapidly fluctuating pore pressure. Therefore, the evolution of pore pressure is closely connected to the type of submarine debris flow. 


\section{Acknowledgement}

This research work is part of the activities of the Schofield Centre at University of

Cambridge. The work presented in the paper is part of the Modelling of Mudslide

Runout Project which was a collaborative project between University of Cambridge and BP.

We thank Dr. Stuart Haigh, (University of Cambridge) and Professor Kenichi Soga,

(UC Berkeley) for comments that greatly improved the research results. We would also like to show our gratitude to Dr. Paul Dimmock (BP) for fully supported this project and sharing his pearls of wisdom with us during the collaboration. 


\title{
Notation
}

\author{
$\alpha \quad$ slope angle \\ $h_{b} \quad$ average slide thickness \\ $\widehat{\mathrm{s}_{\mathrm{u}}} \quad$ dimensionless shear strength \\ V flow velocity \\ $\rho_{d} \quad$ density of the flow slurry \\ $\rho \quad$ density of the ambient fluid \\ g local gravity \\ $\mathrm{Fr}_{\mathrm{d}}$ densimetric Froude number \\ P stagnation pressure \\ $P_{d} \quad$ average submerged debris-load
}




\section{Reference}

Boukpeti, N., White, D. J., Randolph, M. F., \& Low, H. E. (2012). Strength of fine-grained soils at the solid-fluid transition. Geotechnique 62, No. 3, pp. 213-226.

Breien, H., Pagliardi, M., Blasio, F., Issler, D., \& Elverhwi, A. (2007). Experimental studies of subaqueous vs. subaerial debris flows-velocity characteristics as a function of the ambient fluid. Submarine Mass Movements and Their Consequences, pp. 101--110.

Dan, G., Sultan, N., \& Savoye, B. (2007). The 1979 Nice harbour catastrophe revisited: trigger mechanism inferred from geotechnical measurements and numerical modelling. Marine Geology, 245(1), 40-64.

De Blasio, F. V., Engvik, L., Harbitz, C. B., \& Elverhøi, A. (2004). Hydroplaning and submarine debris flows. Journal of Geophysical Research: Oceans (19782012), 109(C1).

Hampton, M. A. (1972). The role of subaqueous debris flow in generating turbidity currents. Journal of Sedimentary Research, 42(4).

Hampton, M., Lee, H., \& Locat, J. (1996). Submarine landslides. Reviews of Geophysics 34(1), pp. 33--59. 
Ilstad, T., Elverhri, A., Issler, D., \& Marr, J. (2004b). Subaqueous debris flow behaviour and its dependence on the sand/clay ratio: a laboratory study using particle tracking. Marine Geology 213(1-4), pp. 415--438.

Ilstad, T., Marr, J., Elverhri, A., \& Harbitz, C. (2004a). Laboratory studies of subaqueous debris flows by measurements of pore-fluid pressure and total stress. Marine Geology, 213(1-4), pp. 403--414.

Kafle, J., Pokhrel, P. R., Khattri, K. B., Kattel, P., Tuladhar, B. M., \& Pudasaini, S. P. (2016). Landslide-generated tsunami and particle transport in mountain lakes and reservoirs. Annals of Glaciology, 57(71), 232-244.

Locat, J., \& Demers, D. (1988). Viscosity, yield stress, remolded strength, and liquidity index relationships for sensitive clays. Canadian Geotechnical Journal 25(4): 799-806.

Locat, J., \& Lee, H. (2000). Submarine landslides: advances and challenges. Canadian Geotechnical Journal. 39(1), pp. 193--212.

Marr, J., Harff, P., Shanmugam, G., \& Parker, G. (2001), Experiments on subaqueous sandy gravity flows: The role of clay and water content in flow dynamics and depositional structures. Geological Society of America Bulletin 113(11), pp. 1377. 
Marr, J. G., Elverhøi, A., Harbitz, C., Imran, J., \& Harff, P. (2002). Numerical simulation of mud-rich subaqueous debris flows on the glacially active margins of the Svalbard-Barents Sea. Marine Geology, 188(3), 351-364.

Masson, D., Harbitz, C., Wynn, R., Pedersen, G., \& Lwvholt, F. (2006). Submarine landslides: processes, triggers and hazard prediction. Philosophical Transactions of the Royal Society A: Mathematical, Physical and Engineering Sciences, 364, pp. 2009-2039.

Mohrig, D., Ellis, C., Parker, G., Whipple, K., \& Hondzo, M. (1998), Hydroplaning of subaqueous debris flows. Geological Society of America Bulletin 110(3), pp. 387.

Mohrig, D., \& Marr, J. G. (2003). Constraining the efficiency of turbidity current generation from submarine debris flows and slides using laboratory experiments. Marine and Petroleum Geology, 20(6), 883-899.

Pudasaini, S. P., \& Hutter, K. (2007). Avalanche dynamics: dynamics of rapid flows of dense granular avalanches. Springer Science \& Business Media.

Pudasaini, S. P. (2014). Dynamics of submarine debris flow and tsunami. Acta Mechanica, 225(8), 2423-2434. 
Schwab, W. C., Lee, H. J., Twichell, D. C., Locat, J., Nelson, C. H., McArthur, W. G., \& Kenyon, N. H. (1996). Sediment mass-flow processes on a depositional lobe, outer Mississippi Fan. Journal of Sedimentary Research, 66(5). 


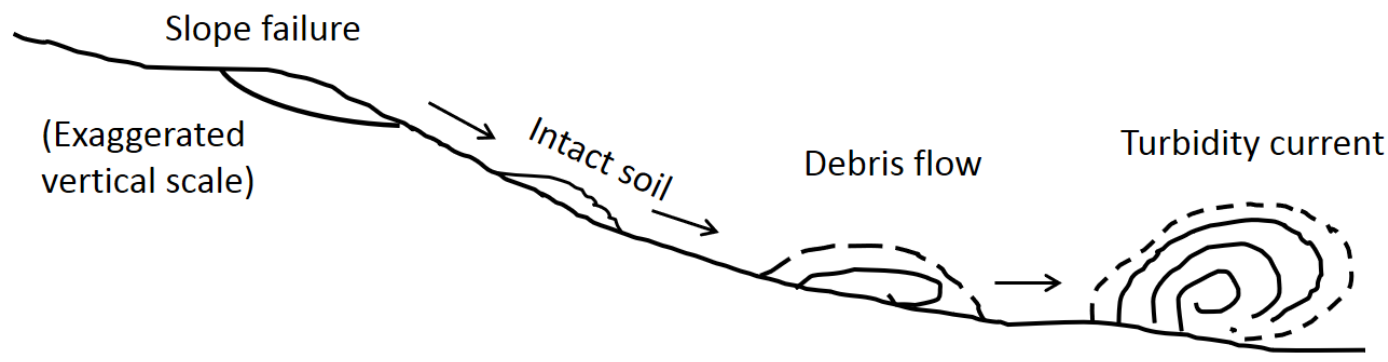

Figure 1: Schematic diagram of key submarine slide characteristics (after Boukpeti et al. 2012)

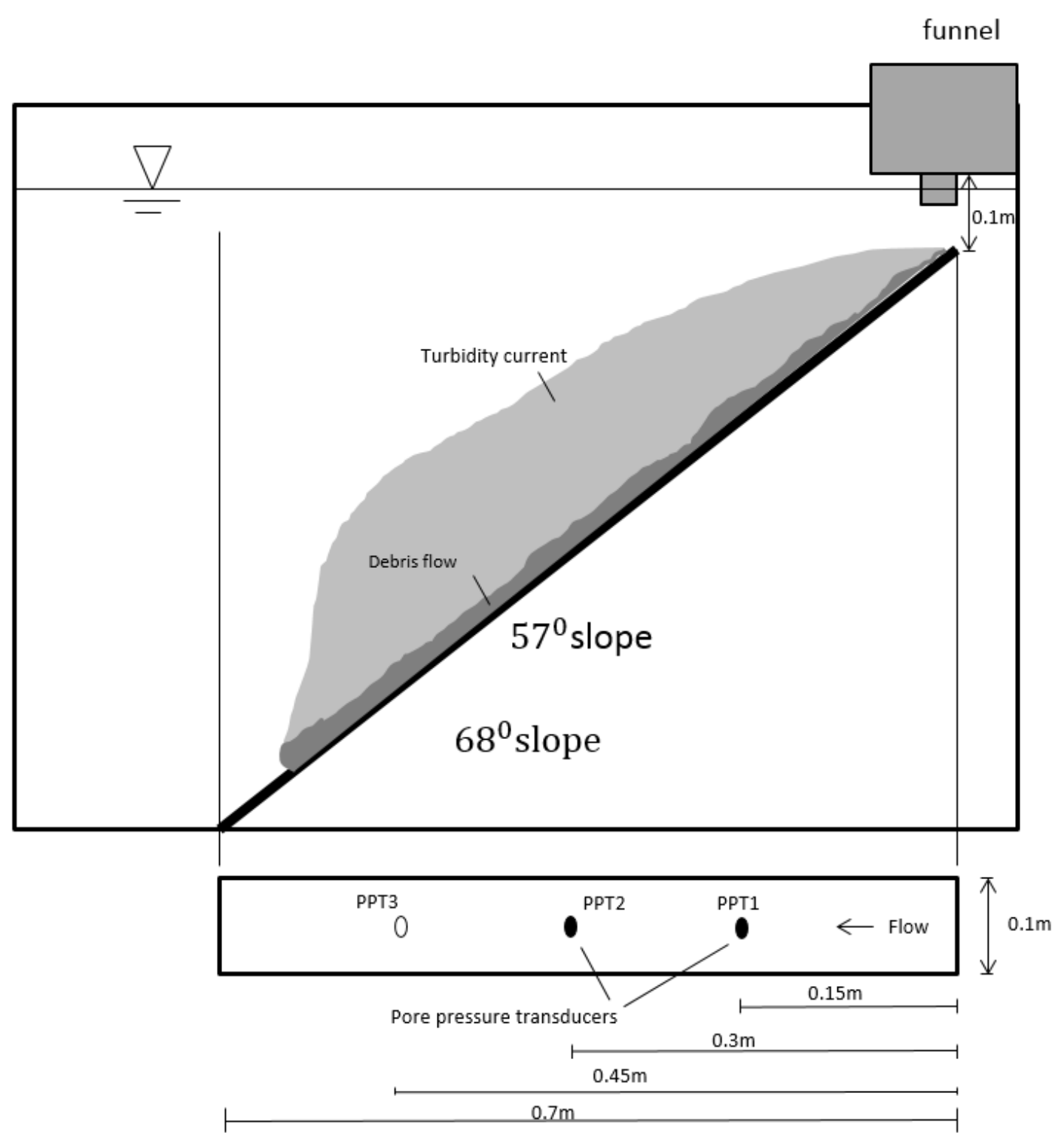

Figure 2: Illustration of the experiment. 


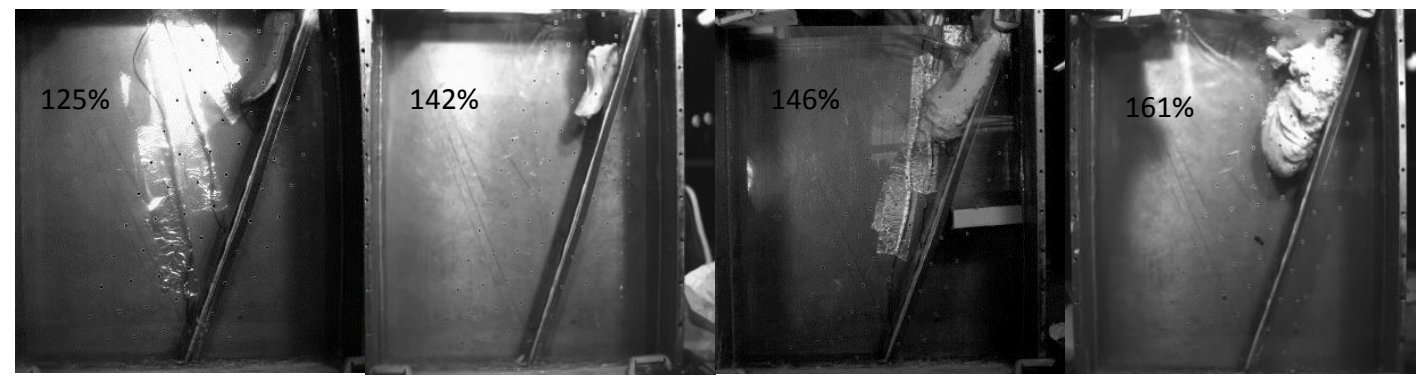

(a)
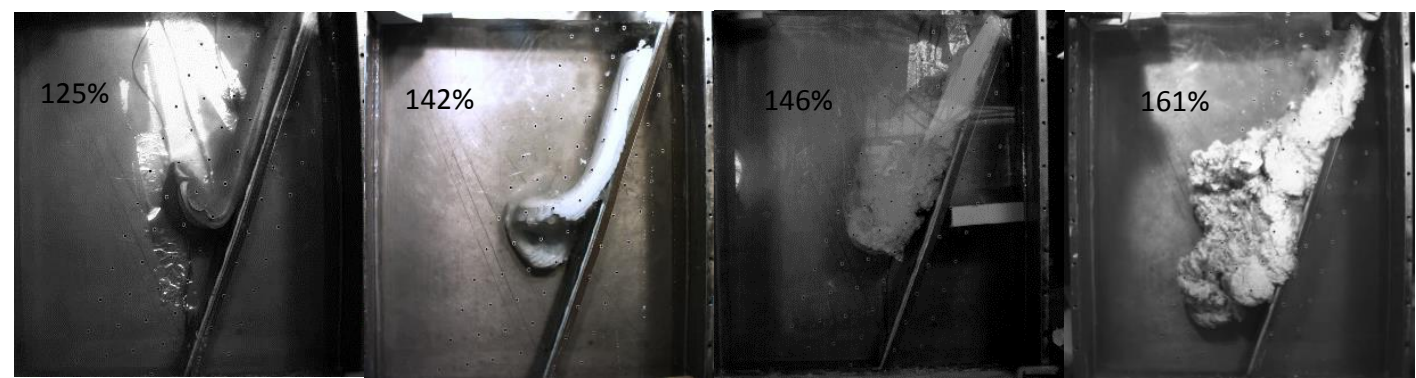

(b)

Figure 3 First series of debris flows (slope angle of $68^{\circ}$ ) with different water content at (a) $15 \mathrm{~cm}$ and (b) $30 \mathrm{~cm}$ downslope from the funnel gate

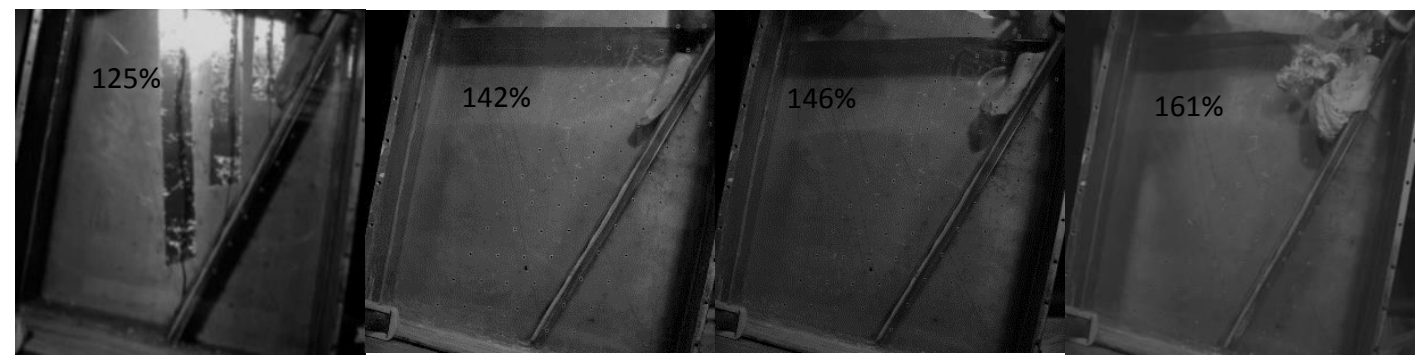

(a)

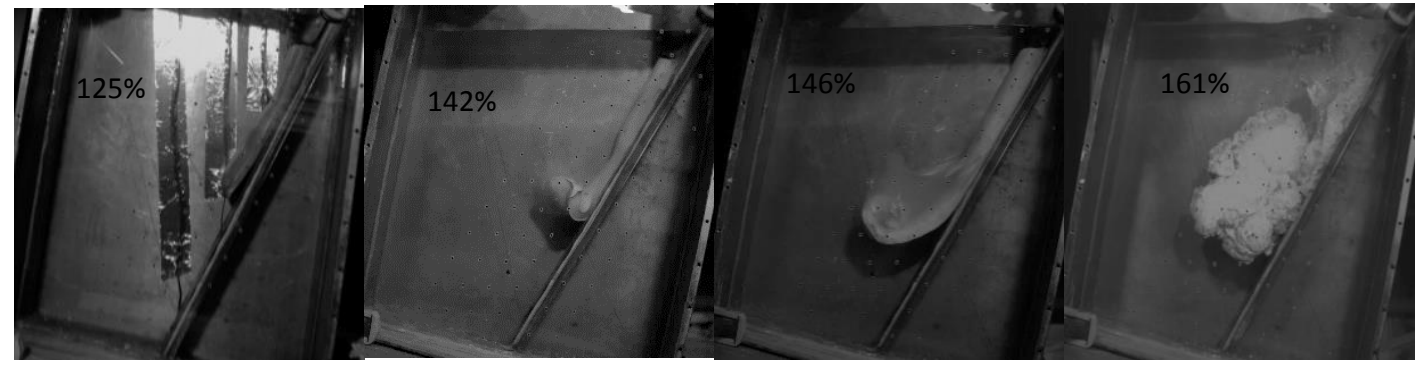

(b)

Figure 4: Second series of debris flows (slope angle of $57^{\circ}$ ) with different water content at (a) $15 \mathrm{~cm}$ and (b) $30 \mathrm{~cm}$ downslope from the funnel gate 

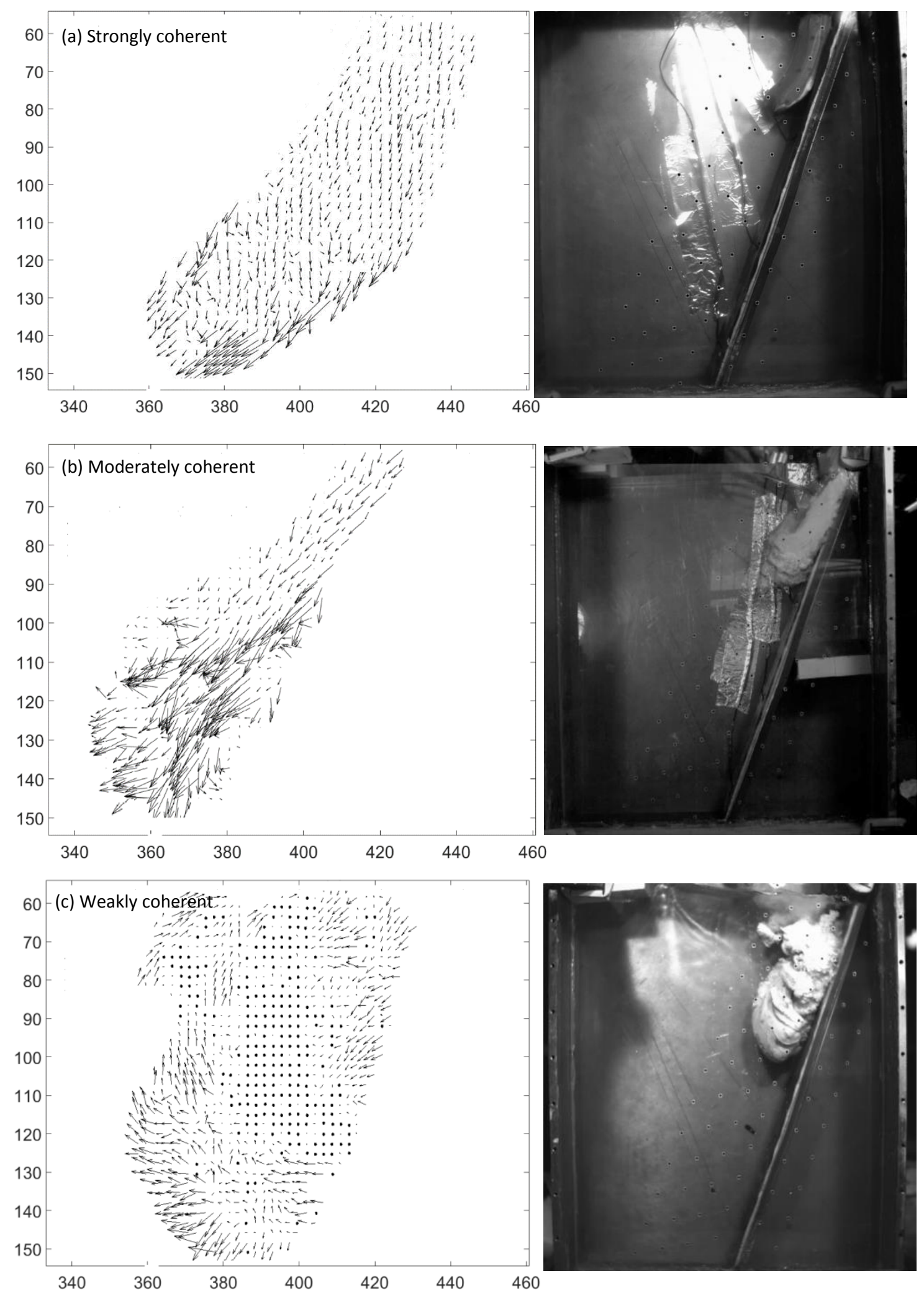

Figure 5: PIV analysis of the behaviour of three different slurries with water content: (a) strongly coherent $(125 \%)$; (b) moderately coherent $(146 \%)$; (c) weakly coherent $(161 \%)$ from first series test (slope angle of $68^{0}$ ). Coordinate units are in $\mathbf{m m}$ 


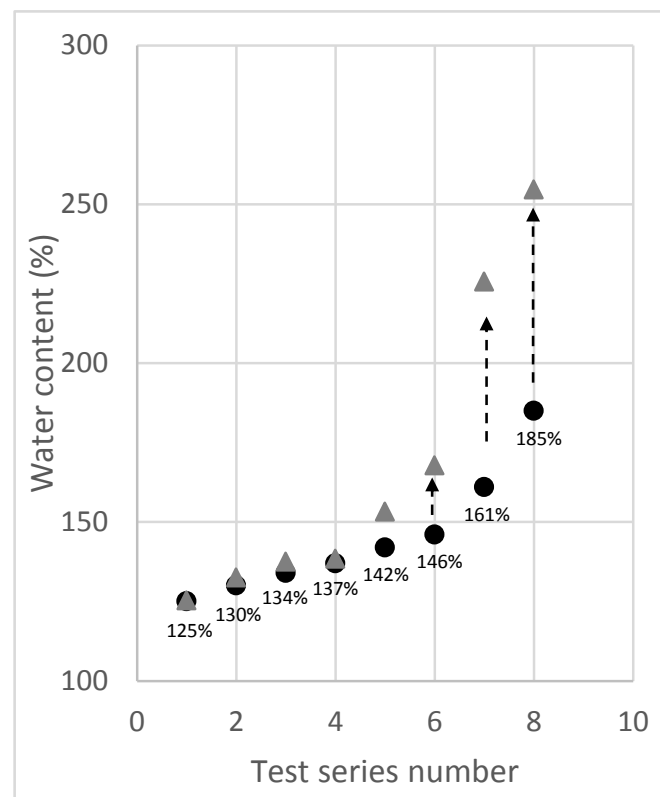

- Initial Water Content $\Delta$ Final water content

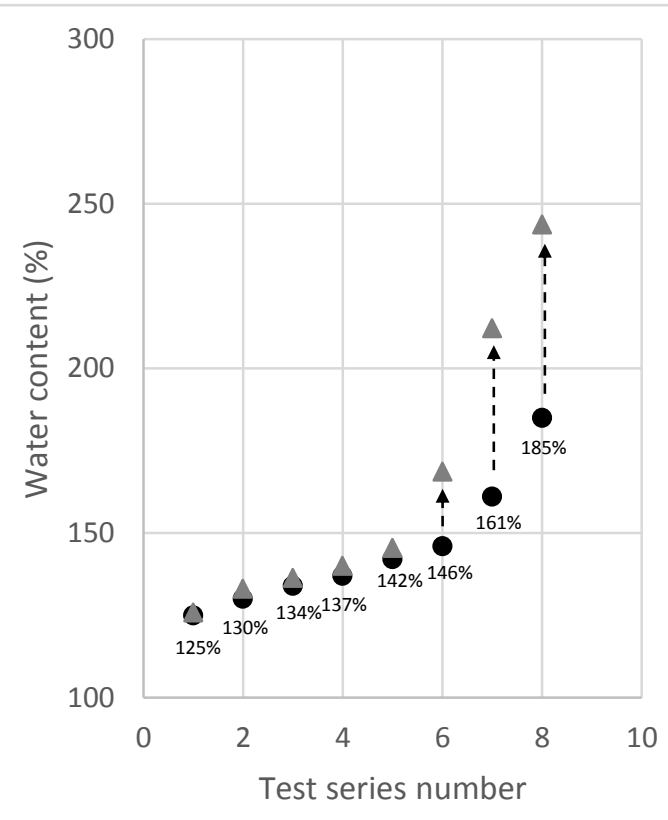

- Initial water content $\Delta$ Final water content

(a)

(b)

Figure 6: Water content of debris flow before and after test: (a) slope angle $\mathbf{6 8}^{\mathbf{0}}$; (b) slope angle $57^{0}$ 


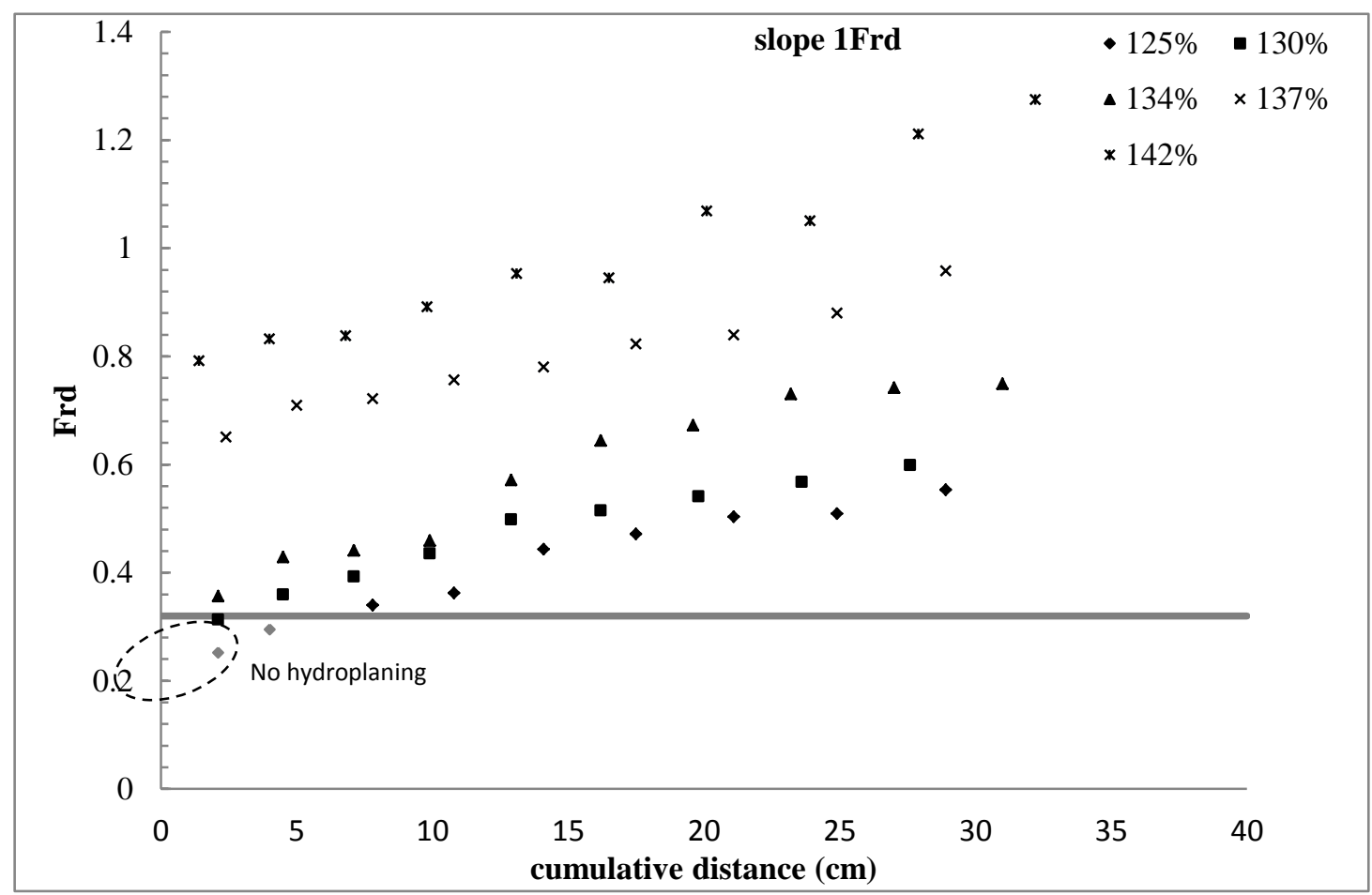

(a) Test series $1\left(\right.$ slope $\left.68^{0}\right)$

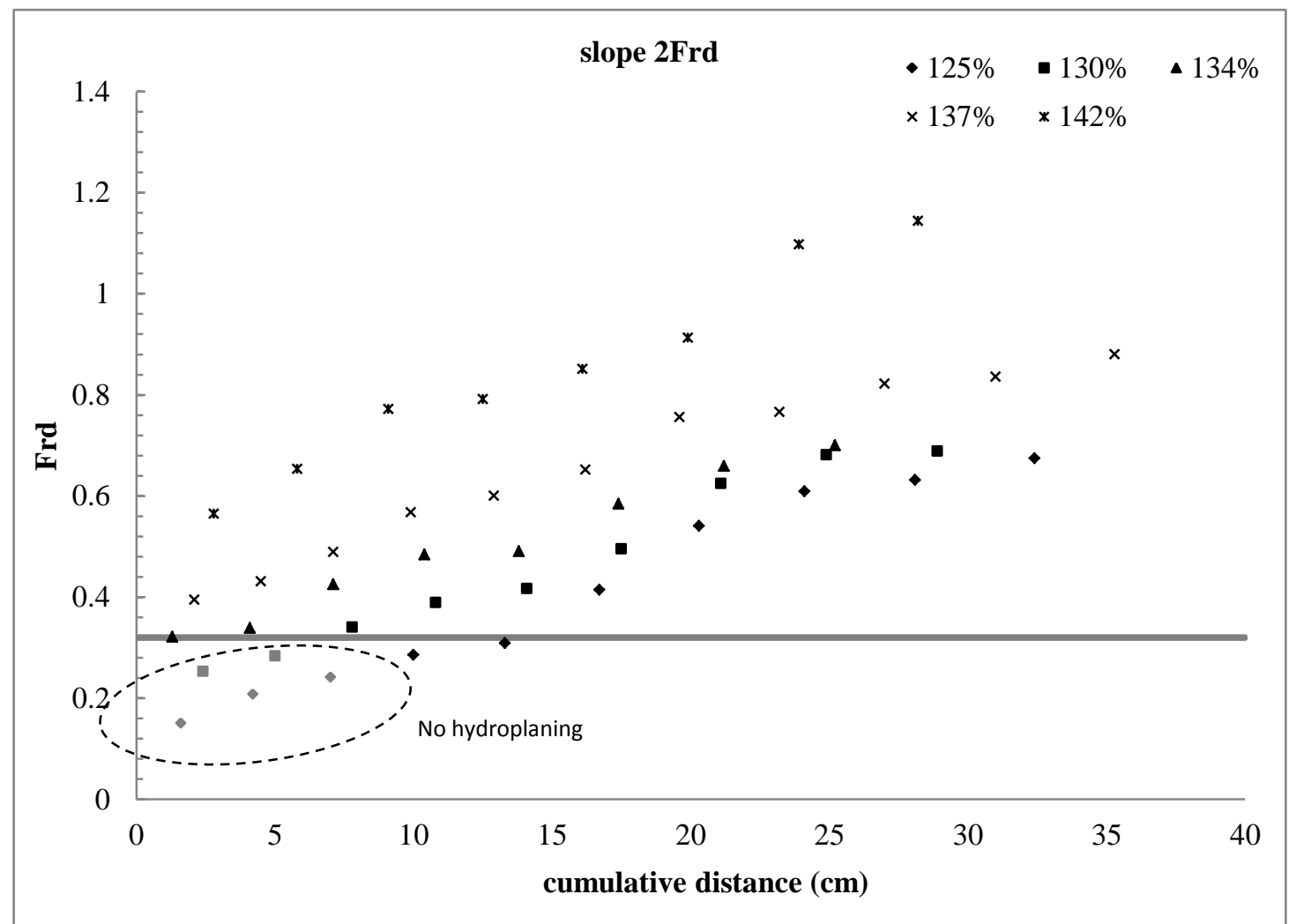

(b) Test series $2\left(\right.$ slope $\left.57^{0}\right)$

Figure 7: Values of the densimetric Froude number $F_{d}$ for (a) Test series 1; and (b) Test series 2 


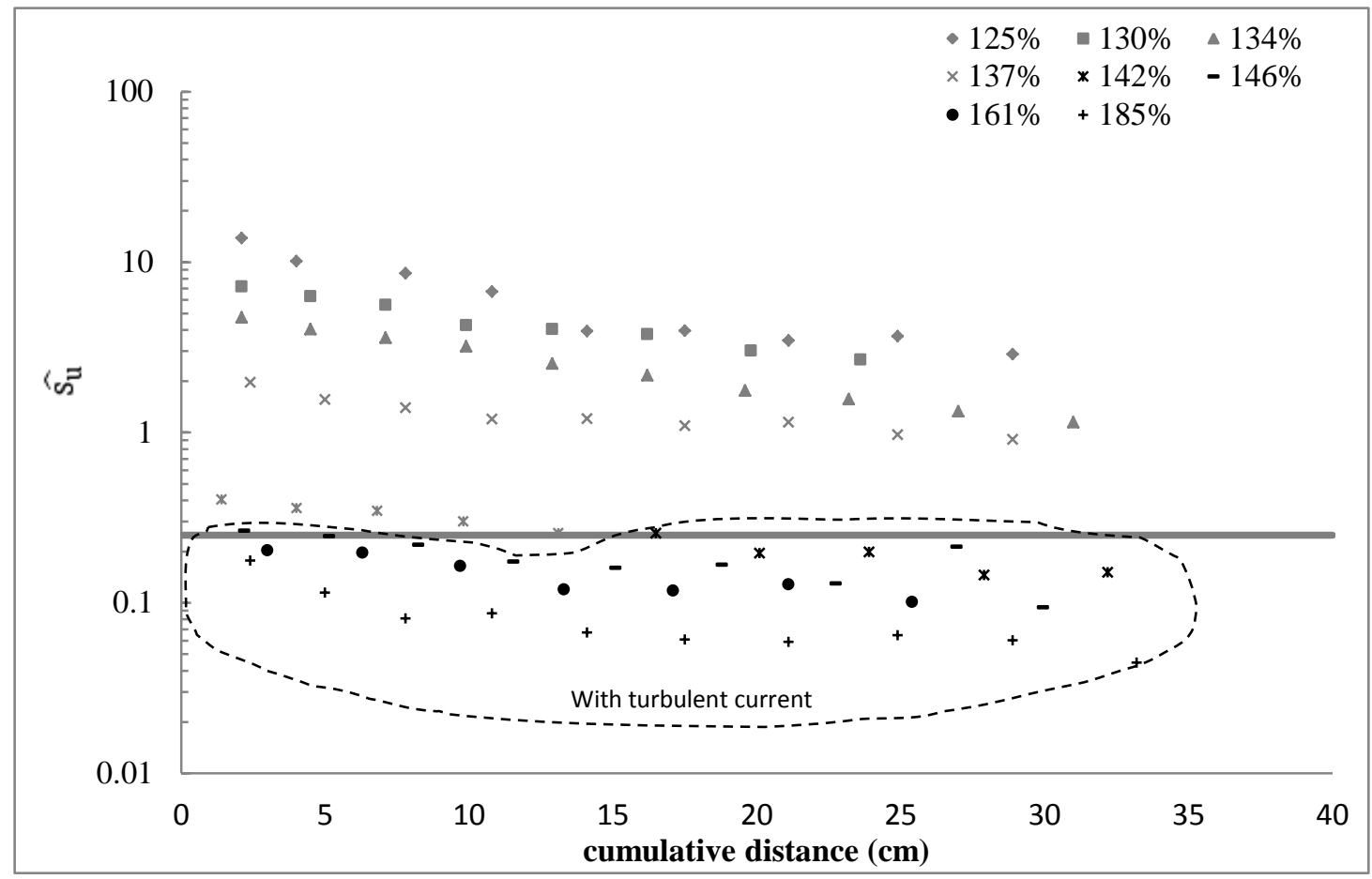

(a) Test series 1 (slope $68^{0}$ )

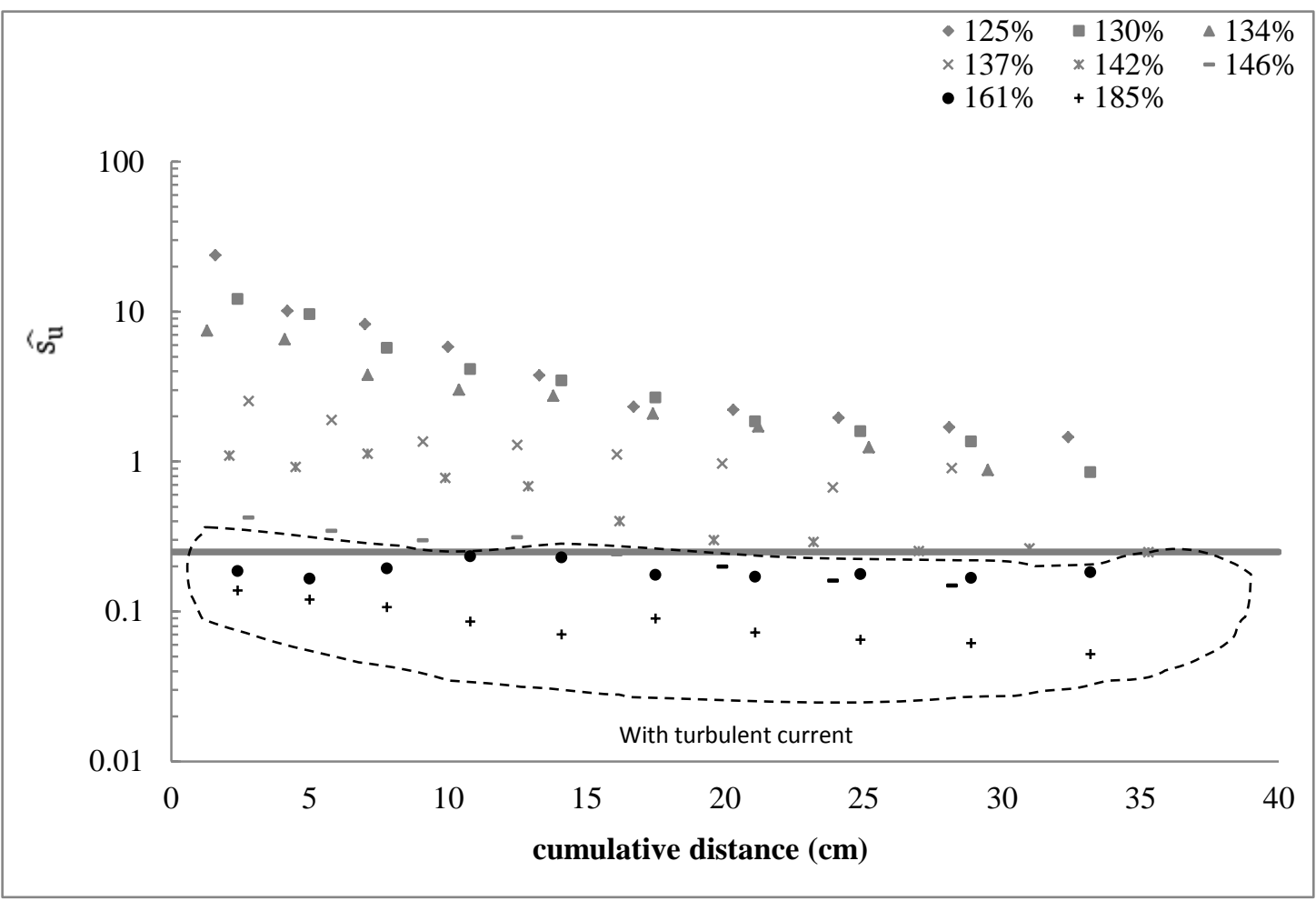

(b) Test series $2\left(\right.$ slope $57^{0}$ )

Figure 8: Values of the dimensionless shear strength, $\widehat{\mathbf{s}_{\mathrm{u}}}$ for (a) Test series 1; and (b) Test series 2 


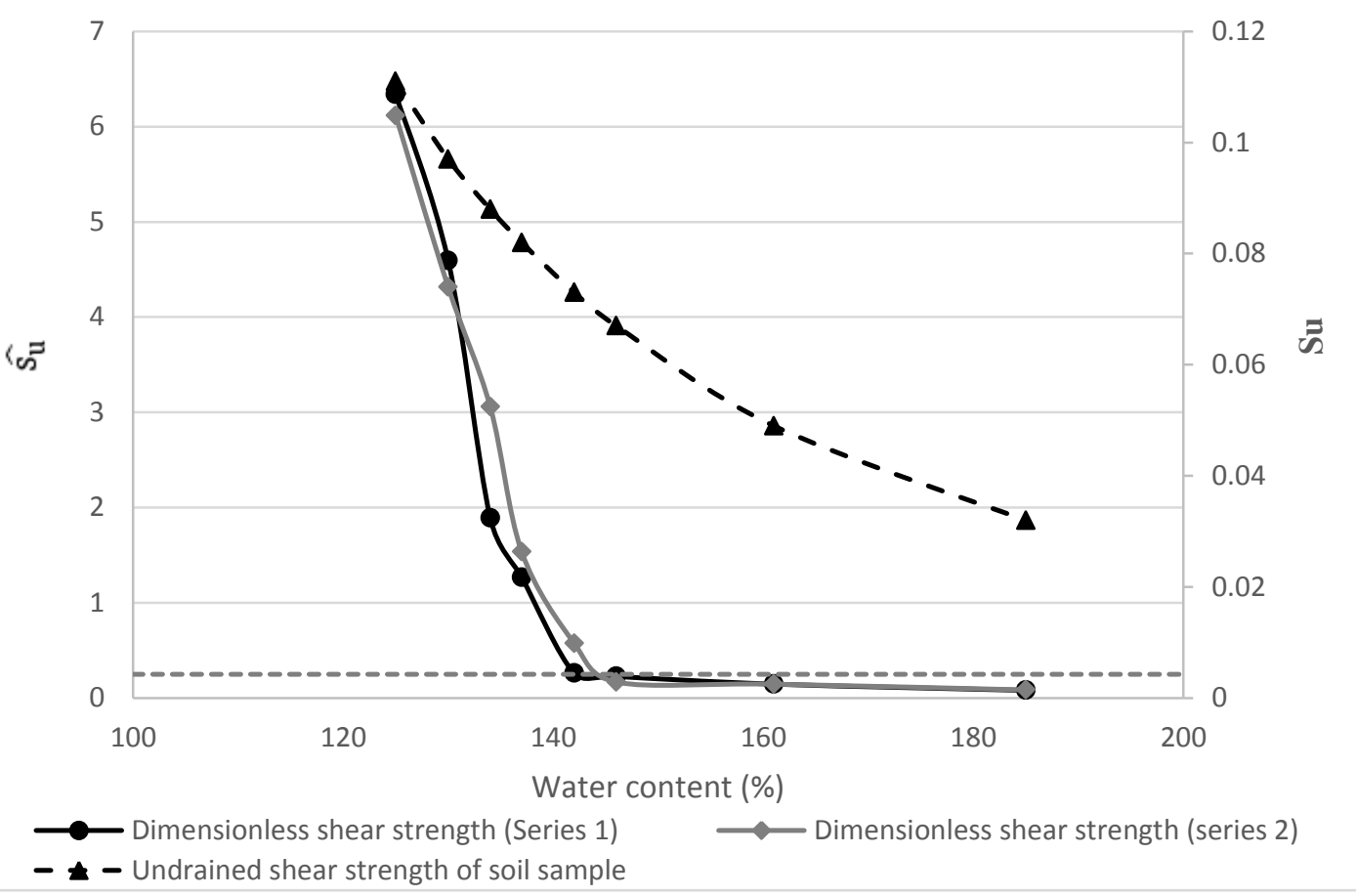

Figure 9: Average values of the dimensionless shear strength, $\widehat{\mathrm{s}_{\mathrm{u}}}$ for different water content 


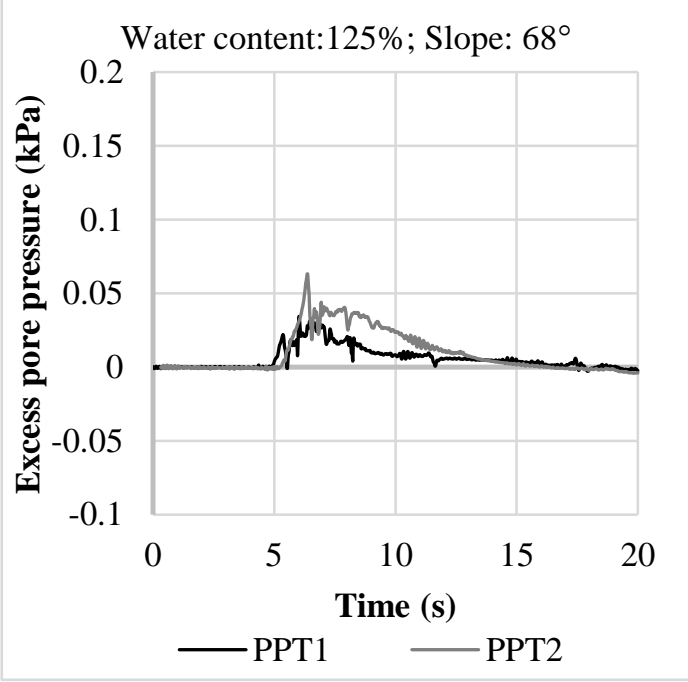

(a)

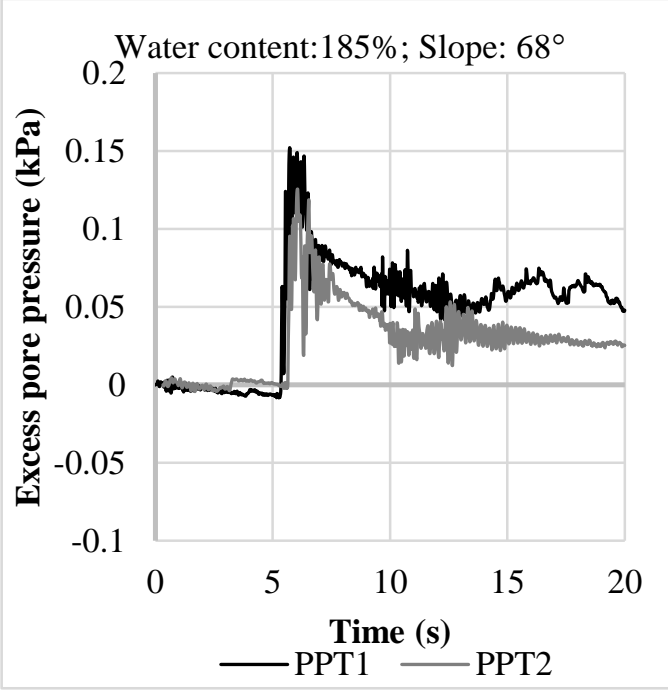

(c)

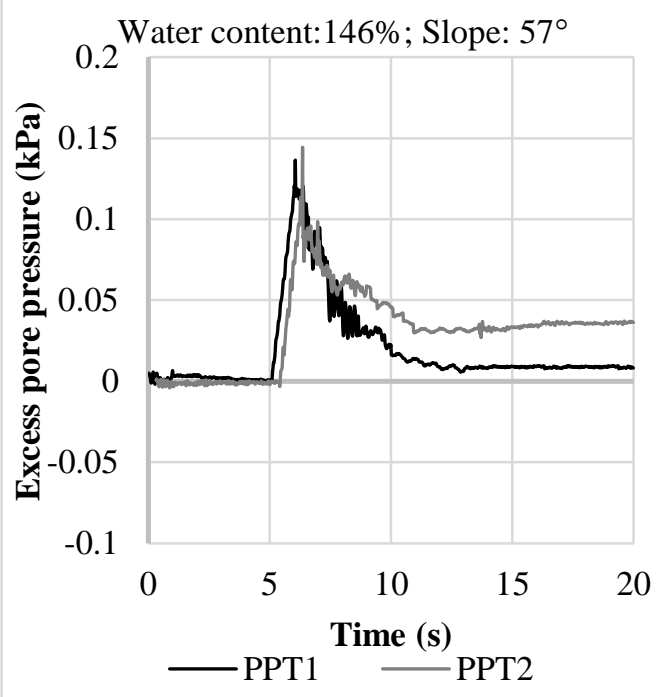

(e)

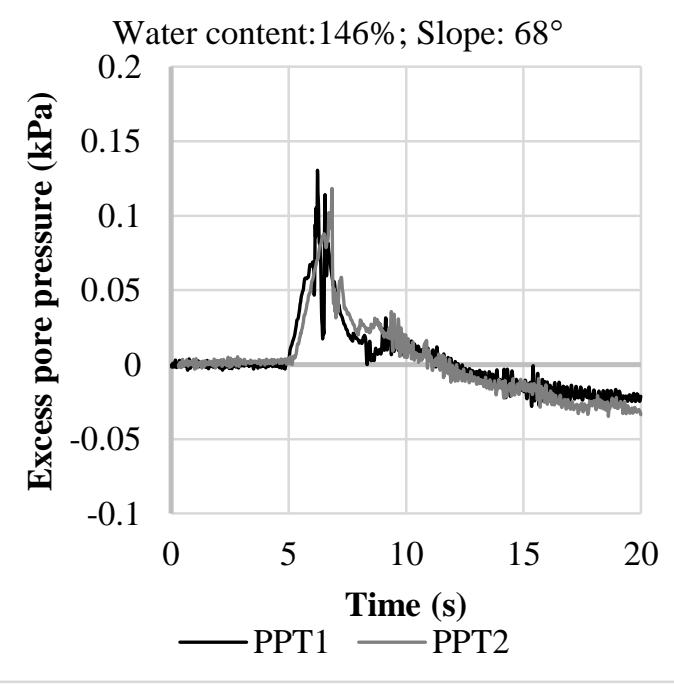

(b)

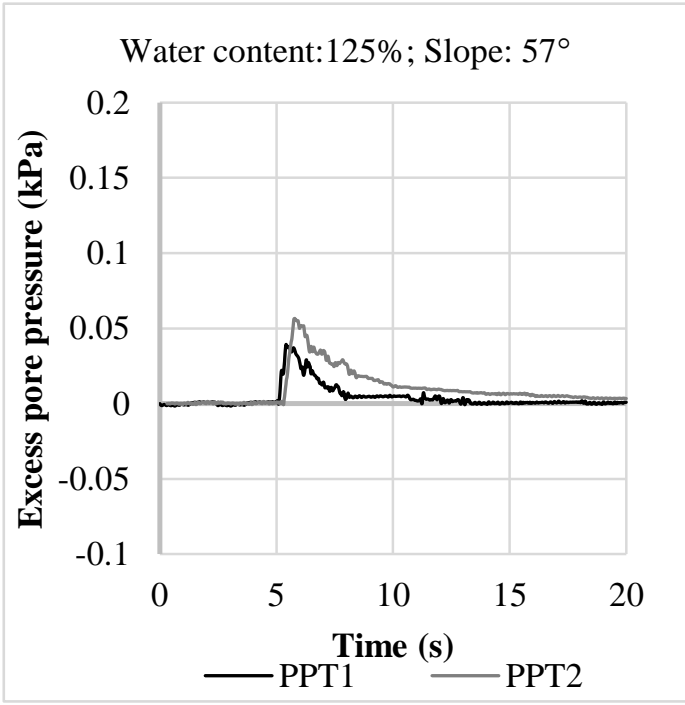

(d)

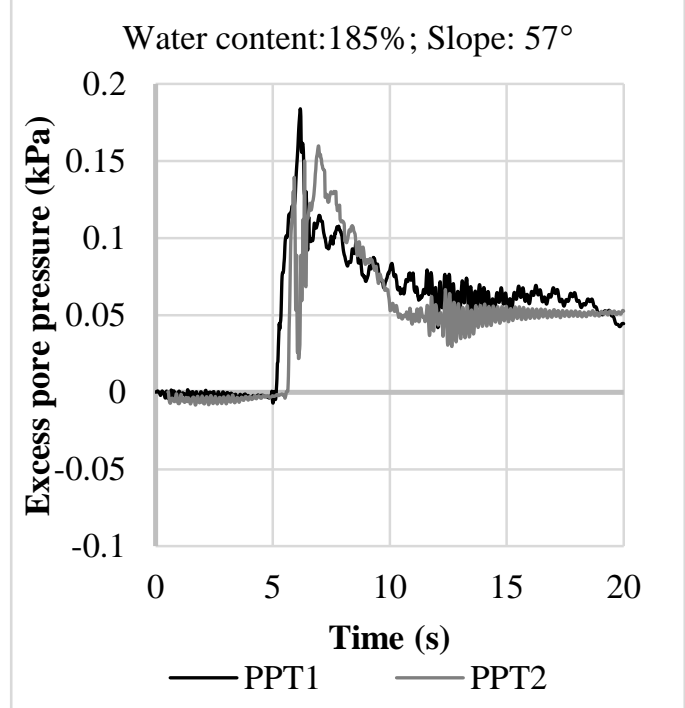

(f)

Figure 10: Pore pressure along the bed under the sliding debris 
